\title{
Antioxidative Activities of Palm Sugar-Like Flavouring
}

\author{
Nur Aniqah Muhamad Amin ${ }^{1}$, Wan Aida Wan Mustapha*,1, Mohamad Yusof Maskat ${ }^{1}$ and \\ Ho Chun Wai ${ }^{2}$
}

\author{
${ }^{I}$ School of Chemical Sciences and Food Technology Faculty of Science and Technology, Universiti Kebangsaan Malay- \\ sia, 43600 Bangi, Selangor Darul Ehsan, Malaysia; ${ }^{2}$ Department of Food Science and Nutrition, Faculty of Applied \\ Sciences, University College Sedaya International, 56000 Kuala Lumpur, Malaysia
}

\begin{abstract}
Maillard reaction products have been considered to have antioxidant capacities due to the reductones compound formations which contribute to antioxidant activity. Besides caramelisation, Maillard reaction takes place during the production of palm sugar. This paper reports the antioxidative activity of palm sugar-like flavourings and the commercial palm sugar (CPS) which was obtained from Pahang by using different types of methods. Formulation of palm sugarlike flavourings which had been optimised was obtained from the previous studies. Palm sugar-like flavourings (PSLFs) were prepared from sucrose and selected amino acids (Asparagine, Glutamine, Arginine and Lysine) at various ratios with buffer solutions ( $\mathrm{pH} 7.86$ ), heated at $143^{\circ} \mathrm{C}$ for 116 minutes. The results revealed that the PSLF (C) showed a significant difference $(\mathrm{p}<0.05)$ in reducing power, thiobarbituric acid (TBA) test, and radical scavenging activity (DPPH) compared to other formulations of PSLF and commercial palm sugar.
\end{abstract}

Keywords: Palm sugar-like flavouring, antioxidative activity, radical scavenging activity (DPPH), reducing power, thiobarbituric acid (TBA).

\section{INTRODUCTION}

Antioxidant has become a very prominent topic in health consumption. Research on antioxidant in common food products have proven that disease fighting properties may be found in almost all fruits and vegetables or even processed food. As long as food had been cooked, Maillard reaction has played a very crucial role in giving good appearance and taste [1] and has been shown to produce antioxidant components as well [2].

Production of palm sugar-like flavourings is also related to the Maillard reaction process. The Maillard reaction involved in the formation of brown pigments due to the condensation between the carbonyl groups of reducing sugar and aldehydes and ketones, the free amino groups of lysine and/or other free amino acids (such as amino acids, peptides and proteins) or any nitrogenous compound [3,4]. A lot of work has been carried out in investigating the antioxidant activity of Maillard reaction product in a model system and also in other foods, such as in beer [5] and coffee [6]. The development of a brown colour called "melanoidins" was an extremely important and obvious feature of the extent of the advanced Maillard reaction [7]. It had been reported to have antioxidant activity through scavenging oxygen radicals or chelating metals [8]. Through in vivo studies, it has been shown that Maillard reaction products were capable in contributing as reducing agents [9], metal chelators [10] and radical scavengers [11].

Besides improving the flavour, colour and texture of the food product, Maillard reaction products also substantially

*Address correspondence to this author at the School of Chemical Sciences and Food Technology, Faculty of Science and Food Technology, Universiti Kebangsaan Malaysia, 43600 Bangi, Selangor Darul Ehsan, Malaysia; Tel: 603-89213870; Fax: 603-89213232; E-mail: wawm@ukm.my contribute to the shelf-life of heat-treated foods [12]. Maillard reaction products have been used to prevent lipid oxidation in many products and exhibit antioxidative activity in meat products $[13,14]$. The oxidation of singlet oxygen generated by exposing methylene blue to light was strongly inhibited by fructose-tryptophan Maillard reaction products and by tryptophan and this suggests that the scavenging of active oxygen species by Maillard reaction products is an important mechanism of the antioxidant [15]. Bedinghaus \& Ockerman [14] found that reducing sugars and free amino acids generated antioxidant compounds in cooked ground pork patties.

The present study was conducted to investigate the antioxidant activity of various formulations of palm sugar-like flavouring (PSLF) and commercial palm sugar (CPS) using different types of methodology.

\section{MATERIALS AND METHODOLOGY}

\section{Preparation of Palm Sugar-Like Flavouring}

Five samples of palm sugar like-flavourings were prepared according to the formulations and parameters which had been optimised by Ho et al. [16]. Commercial palm sugar was obtained from Pahang, Malaysia.The reactant materials (Table 1) were dissolved in $100 \mathrm{ml}$ of $0.2 \mathrm{M}$ phosphate buffer ( $\mathrm{pH}$ 7.8) solution. The mixture was then heated in half covered reaction vessel $(500 \mathrm{ml})$ which was immersed in $1 \mathrm{~L}$ of silicon oil at $143^{\circ} \mathrm{C}$ for 116 minutes. The samples were kept in $25 \mathrm{ml}$ screw cap bottles and stored at $18^{\circ} \mathrm{C}$.

\section{Measurement of pH}

$\mathrm{pH}$ values were measured by using a $\mathrm{pH}$ meter (Radiometer Analytical, model PHM 210). Approximately 
Table 1. Formulation Used to Prepare Palm-Sugar Like Flavouring

\begin{tabular}{|c|c|c|c|c|c|}
\hline \multirow[t]{2}{*}{ Reactant Materials } & \multicolumn{5}{|c|}{ Samples (mmol) } \\
\hline & $\mathbf{A}$ & B & $\mathbf{C}$ & D & $\mathbf{E}$ \\
\hline Sucrose & 12.75 & 12.65 & 12.68 & 12.68 & 12.77 \\
\hline Asparagine & 2.55 & 2.53 & 2.55 & 2.55 & 2.53 \\
\hline Glutamine & 2.99 & 2.59 & 2.23 & 2.23 & 2.26 \\
\hline Arginine & 0.62 & 0.62 & 0.62 & 0.62 & 0.61 \\
\hline Lysine & 0.65 & 0.48 & 0.48 & 1.01 & 0.95 \\
\hline
\end{tabular}

0.5 gram of each sample was dissolved in $10 \mathrm{ml}$ of distilled water and the analysis was made in triplicates.

\section{Extraction of Antioxidant Maillard Reaction Products}

The extraction of Maillard reaction products (MRP) from PSLF was carried out according to the method of Yusuf and Romeo [8]. The sample was dissolved in distilled water $(40 \mathrm{ml} / \mathrm{g})$ using vortex. The mixture was centrifuged at $26,000 \mathrm{~g}$ for 30 minutes at $4^{\circ} \mathrm{C}$. Supernatant was collected and kept at $4^{\circ} \mathrm{C}$ for further analysis. Each sample was prepared in triplicates.

\section{Determination of Browning Intensity}

Browning intensity of PSLF samples was measured according to Ajandouz et al. [17] with slight modifications. Appropriate dilution (sample extract/ distilled water) (1: 9, $\mathrm{v} / \mathrm{v}$ ) was prepared using distilled water and the absorbance was measured at $420 \mathrm{~nm}$ using UV-Vis spectrophotometer (Shimadzu, model UV-2450). The dilutions were made in order to obtain optical density of less than 1.5 [8].

\section{Determination of DPPH Radical Scavenging Activity}

The 2,2-diphenyl-1-picrylhydrazyl (DPPH) radical scavenging activity was determined according to the method of Wittayachai, et al. [18]. Approximately, 80 $\mu$ l of PSLF extract was added with $320 \mu \mathrm{l}$ distilled water and $2 \mathrm{ml}$ of 0.12 $\mathrm{mM}$ DPPH in methanol. The mixtures were then mixed vigorously and allowed to stand at room temperature in the dark for 30 minutes. The absorbance of the sample mixture was then measured at $517 \mathrm{~nm}$ using the UV-Vis spectrophotometer (Shimadzu, model UV-2450). The control sample was prepared in the same manner as the preparation of sample mixtures except that deionised water was used instead of the PSLF samples. The blank sample was handled in the same manner but deionised water was used instead of a DPPH solution.

Percentage of DPPH radical scavenging activity =

$$
1-\left[\frac{\text { Absorbance of blank }}{\text { Absorbance of samples }}\right] \times 100
$$

\section{Determination of Reducing Activity}

The reducing power of PSLF was determined according to the method of Wittayachai et al. [18]. Approximately, 1 $\mathrm{ml}$ of $0.2 \mathrm{M}$ phosphate buffer $(\mathrm{pH} \mathrm{6.6)}$ and $1 \mathrm{ml}$ of $1 \%(\mathrm{w} / \mathrm{v})$ potassium ferricyanide were added to $1 \mathrm{ml}$ of PSLF extract sample. The reaction mixture was then incubated at $50^{\circ} \mathrm{C}$ in a water bath for 20 minutes. Subsequently, $1 \mathrm{ml}$ of $10 \%$ acid trichloroacetic acid was added to the mixture. The mixtures were centrifuged at $750 \mathrm{~g}$ using centrifuge (KUBOTA, model 2450). Supernatant $(1 \mathrm{ml})$ was mixed with distilled water (1 $\mathrm{ml})$ and $200 \mu \mathrm{l}$ of ferric chloride. The absorbance of the mixture was measured at $700 \mathrm{~nm}$.

\section{Ferric Thiocyanate Method}

The ferric thiocyanate method (FTC) was carried out according to Mohd Zin et al. [19]. Samples of $4 \mathrm{mg}$ were dissolved in $99.5 \%$ ethanol $(4.1 \mathrm{ml})$ and mixed with $2.5 \%$ linoleic acid, $0.05 \mathrm{M}$ phosphate buffer $(\mathrm{pH} 7.0,8 \mathrm{ml})$ and distilled water $(3.9 \mathrm{ml})$ and kept in screw cap bottles and incubated in a temperature controlled water bath at $45^{\circ} \mathrm{C}$, overnight. Subsequently, $9.7 \mathrm{ml}$ of $75 \%$ ethanol and $0.1 \mathrm{ml}$ of $30 \%$ ammonium thiocyanate were added into $0.1 \mathrm{ml}$ of the incubated sample, followed by $0.02 \mathrm{M}$ of ferrous chloride in $3.5 \%$ hydrochloric acid. The mixture was left for 3 minutes. The absorbance was measured at $500 \mathrm{~nm}$ using the UV-Vis spectrophotometer (Shimadzu, model UV-2450).

\section{Thiobarbituric Acid Test (TBA)}

The test was conducted according to the method of Kikozaki \& Nakatani [20]. The same samples prepared for the FTC method were used. A sample solution $(1 \mathrm{ml})$ was mixed with $20 \%$ trichloroacetic acid $(2 \mathrm{ml})$ and thiobarbituric acid solution $(2 \mathrm{ml})$. The mixture was then placed in a boiling water bath for 10 minutes and cooled before it was centrifuged at $3000 \mathrm{rpm}$ for $20 \mathrm{mins}$. Absorbance of supernatant was measured at $532 \mathrm{~nm}$ using the UV-Vis spectrophotometer (Shimadzu, model UV-2450).

Percentage of TBA test $=$

$$
1-\left[\frac{\text { Absorbance of blank }}{\text { Absorbance of samples }}\right] \times 100
$$

\section{The Statistical Analysis}

All experiments were conducted in triplicate and statistical analysis was done according to the SAS (1990) User's Guide. Descriptive statistical analysis was performed by using analysis of variance. Duncan's multiple range tests were used to determine significant differences between the means. Graphs were made by using the Microsoft Excel (Microsoft Corporation). The data were expressed as means \pm S.D. The group differences were evaluated by using t-tests with $\mathrm{p}<0.05$ considered as indicating a statistically significant difference. 
Table 2. The Initial and Final pH Value of Palm Sugar-Like Flavouring and Commercial Palm Sugar

\begin{tabular}{|c|c|c|}
\hline \multirow[t]{2}{*}{ Samples } & \multicolumn{2}{|c|}{ pH Value } \\
\hline & Initial & Final \\
\hline A & $7.92 \pm 0.03$ & $6.31 \pm 0.04$ \\
\hline B & $8.02 \pm 0.02$ & $6.91 \pm 0.02$ \\
\hline $\mathrm{C}$ & $8.00 \pm 0.08$ & $6.15 \pm 0.01$ \\
\hline $\mathrm{D}$ & $8.08 \pm 0.03$ & $6.99 \pm 0.06$ \\
\hline E & $8.74 \pm 0.08$ & $6.90 \pm 0.01$ \\
\hline Commercial Palm Sugar (CPS) & N/A & $5.61 \pm 0.11$ \\
\hline
\end{tabular}

\section{RESULTS AND DISCUSSION}

\section{Analysis of pH}

The $\mathrm{pHs}$ of all PSLF with different initial $\mathrm{pHs}$ decreased significantly $(\mathrm{p}<0.05)$ from their initial values within 116 minutes (Table 2). The interaction between sucrose and amino acids throughout the Maillard reactions was prone to lowering the $\mathrm{pHs}$ value. The reactivity of sugars and amino acids was highly influenced by the $\mathrm{pH}$. The initial $\mathrm{pH}$ value of the model system was considered as a crucial part in the Maillard reaction [21]. The initial $\mathrm{pH}$ of all PSLF samples was more than $\mathrm{pH} 7$. At higher $\mathrm{pH}$, the open chain form of sugar and unprotonated form of amino group, were considered to be the reactive forms of Maillard reactions [22].

The reduction of $\mathrm{pH}$ in Maillard reaction was due to the formation of organic acids such as formic and acetic acids from the degradation of fructose and glucose [23]. This had contributed to the present of $\mathrm{H}^{+}$ion in the system. The lower the $\mathrm{pH}$, the more protonated amino group was present in the mixture. The decreasing level of $\mathrm{pH}$ was in agreement with Apriyantono and Ames [24], Morales and Jimenez-Perez [25] and Benjakul et al. [26] who found that during the Maillard reaction, $\mathrm{pH}$ frequently decreased as the heating time increased.

In Table 2, the lowest final $\mathrm{pH}$ depicted in CPS was probably caused by the $\mathrm{pH}$ value and the composition of palm sap derived from the tropical palm tree [27], and enviromental factors, such as weather, geographic area of plantation, the fertility of soil and the age of palm tree. The uncontrolled temperature and duration of cooking time also influenced the yield of palm sugar.

\section{Analysis of Browning Intensity}

PSLF $\mathrm{C}$ in Fig. (1) showed the highest browning intensity of $0.257 \pm 0.03$ and was significantly different as compared to other PSLFs (A,B,D and E) and CPS $(\mathrm{p}<0.05)$. The degree of browning was usually measured via the absorbance at $420 \mathrm{~nm}$ which was used analytically to assess the extent of the Maillard reaction that has taken place in samples.

Apart from the Maillard reaction, the caramelisation of glucose which contributed to non-enzymatic browning reactions also took place at the same time [26, 28]. However, previous reports [29], showed that the type of amino compounds and reducing sugars, as well as the $\mathrm{pH}$ of the medium, are the factors that mainly affect the rate of the Maillard reaction.

The highest concentration of sucrose in PSLF C rendered the high browning intensity. Sucrose, which is a carbohydrate consist of 1 molecule of glucose and 1 molecule of fructose contributed to the caramelisation process at the early stage of PSLF production. These two reducing sugars would react stimultaneously with amino

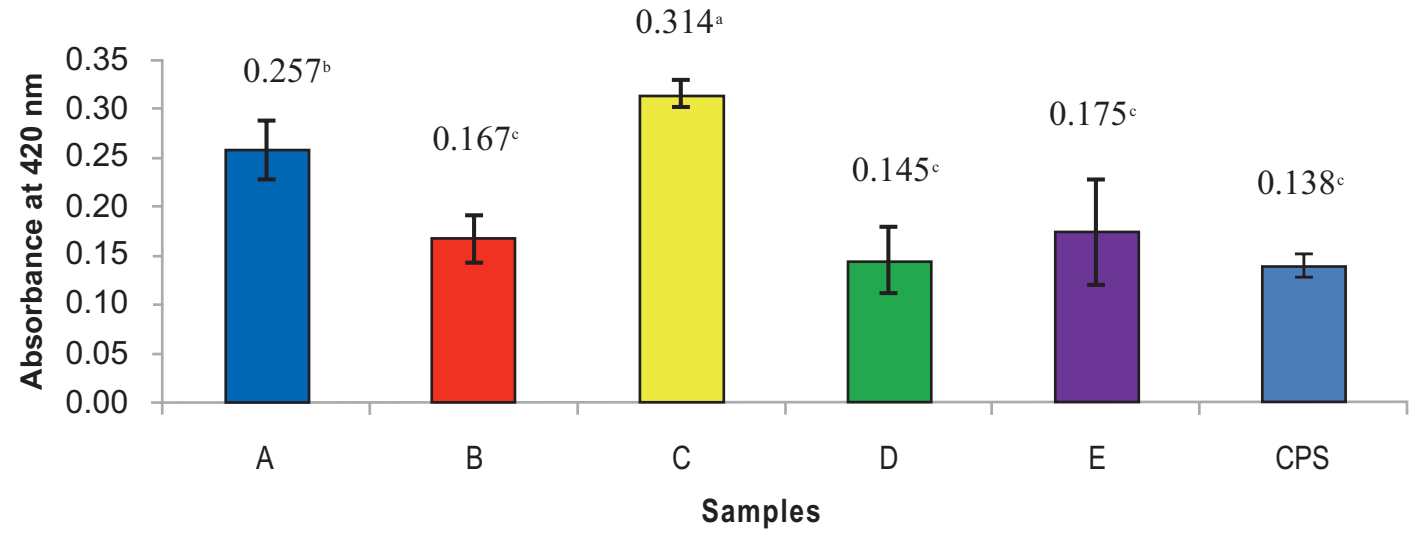

Fig. (1). Browning of Various Formulations of Palm Sugar-Like Flavouring and Commercial Palm Sugar (CPS).

*Values are the means of triplicate analysis.

*Values followed by a different superscript letter are significantly different $(\mathrm{p}<0.05)$. 
acids and in the following Maillard reaction. The browning intensity was found to be dependent on sugar concentration. The browning rate was influenced by the type of reducing sugar involved in the reaction. The reactivity of reducing sugar was reported to decrease in the following order: aldopentose> aldohexoses> ketohexoses> disaccharide [30]. A small amount of reducing sugar was sufficient to cause considerable browning [31]. A previous study reported that the isomerisation and degradation reaction of sugar played an important role [32].

A study on fructose in the Maillard reaction showed that the level of browning intensity was high in fructose as it had many chain structured to give a condensation product, $\mathrm{N}$ glycosylamine [33] which rearranged to form Amadori rearrangement products (ARPs). This reaction step was very important as it could be initiated under mild conditions. Food that had been kept at room temperature may eventually turn brown due to the polymerisation of the degradation products of ARPs. At high temperatures, ARPs can be formed within hours and degrade or react with other food components to produce the characteristic of aroma and the brown colour [34]. Fructose was sensitive neither in the present of nor in the absence of oxygen at the early stage of the Maillard reaction. Hence, the reaction was more extensive in ARP reactions due to the formation of more $\mathrm{N}$-glycosylamine structures. The Amadori form which was decomposed, formed a lot of compounds, including reductones which were very reactive and able to produce florescent compounds which are possible precursor for browning pigment, melanoidins [35]. Brandis et al. [36] found that fructose experience a higher browning intensity as compared to other reducing sugars when it is heated for $60 \mathrm{mins}$ at $120^{\circ} \mathrm{C}$. In the advanced stage of the Maillard reaction, a range of reactions took place, including cyclisations, dehydrations, retroaldolisations, rearrangements, isomerisations and further condensations which ultimately to the formation of melanoidins [23].

According to Ashoor and Zent [37], common amino acids and amides were classified into the Maillard browning produced when they were heated with common reducing sugar. They were high browning producing amino acids, such as lysine, glycine, tryptophan and tyrosine, intermediate browning producing amino acids, like proline, leucine, isoleucine, alanine, hydroxyproline, phenylalanine, methionine, valine, glutamine and asparagine, and low browning producing amino acids of histidine, threonine, aspartic acid, arginine, glutamic acid and cysteine.

Lyisne, a high browning producing amino acid was used in all samples of PSLF. It served as a source of reactive amino groups for the Maillard reactions as it has two $\alpha$ - and $\beta$ - amino groups, it may have higher reactivity than other amino acids [38]. Although, lysine was high in the formulation of PLSF samples D and E, the interactions from intermediate browning producing amino acids (asparagine and glutamine) would render a higher absorbance in other formulations.

\section{Analysis of DPPH Radical Scavenging Activity}

Fig. (2) showed the DPPH radical scavenging activity of PSLF and CPS. Subsequently, there was a significante difference in PSLF and CPS $(\mathrm{p}<0.05)$.

The DPPH-scavenging activity was due to the presence of a compound capable of producing hydrogen atoms [39]. DPPH radical had been scavenged by the Maillard reaction product through the hydrogen process to form stable DPPH$\mathrm{H}$ molecules [40]. The decrease in absorbance value indicated the transfer of hydrogen ion to DPPH radicals. PSLF C depicted a higher percentage, parallel with the higher contribution of $\mathrm{H}^{+}$ion. The colour of the solution would change from purple to yellow when DPPH had received the $\mathrm{H}^{+}$ion [39].

The Maillard reaction, has been known to be associated with the formation of compounds with pronounced antioxidant activity [41]. This could be due to the reductone structure which had been formed as a result of heating. An outcome that is consistent with Yen and Hsieh [42], Murakamie et al. [43], Morales and Jimenez-Perez [25] and Benjakul et al. [26] who also found that Maillard reaction products had DPPH radical scavenging activity.

According to Murakami et al. [43], the radical scavenging activity in the late stage of the Maillard reaction

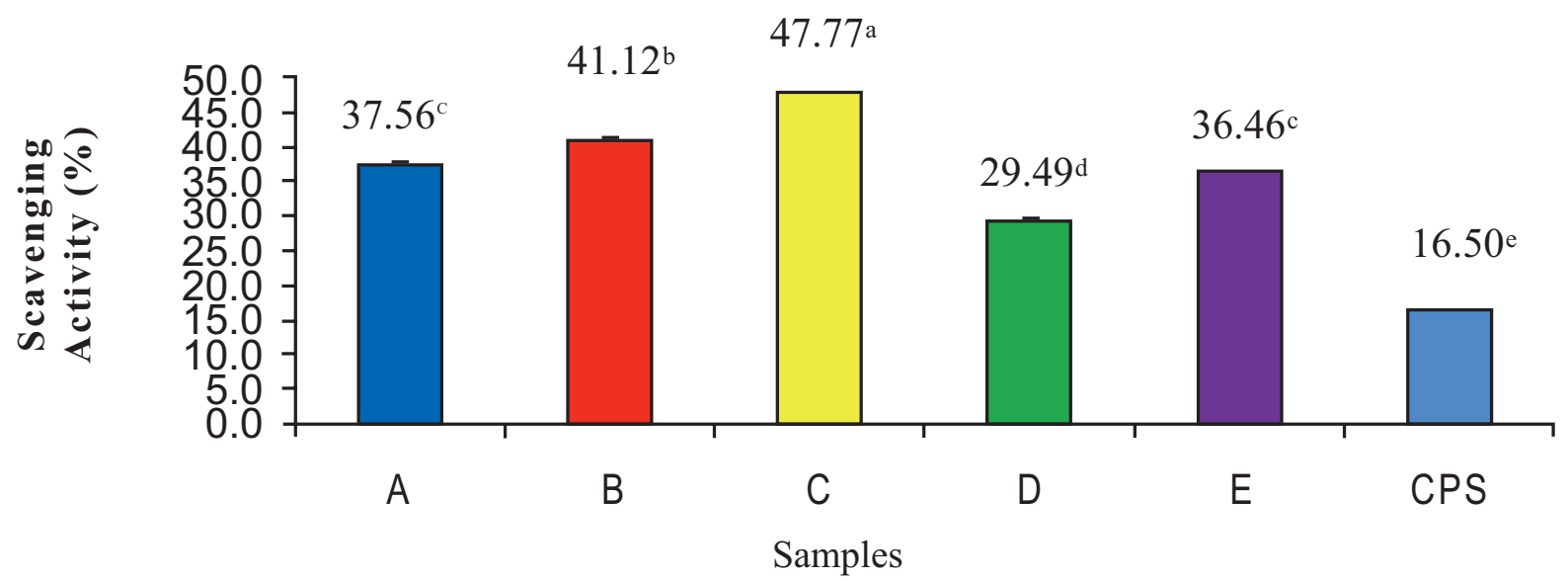

Fig. (2). Percentage (\%) of DPPH Radical-Scavenging Activities of Various Formulations of Palm Sugar-Like Flavouring and Commercial Palm Sugar (CPS).

*Values are the means of triplicate analysis.

*Values followed by a different superscript letter are significantly different $(\mathrm{p}<0.05)$. 


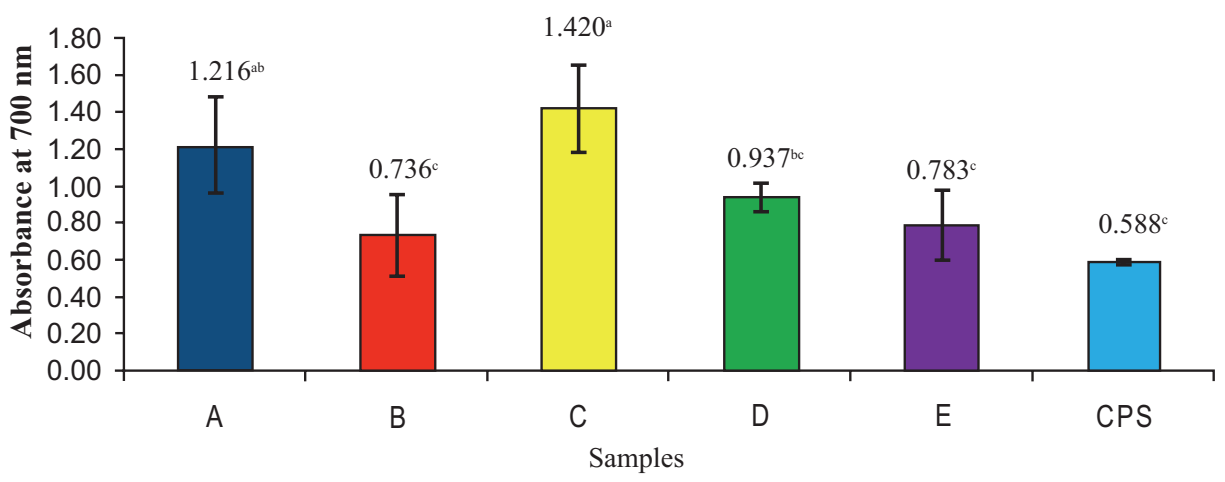

Fig. (3). Reducing Power of Various Formulations of Palm Sugar-Like Flavouring and Commercial Palm Sugar (CPS).

*Values are the means of triplicate analysis.

*Values followed by a different superscript letter are significantly different $(\mathrm{p}<0.05)$.

was derived from the brown pigments. Hayase et al. [44] speculated that melanoidins showed a greater rate of scavenging hydroxyl radicals as a result of the presence of reductones, enamides or pyrrole-like structure in the melanoidins. In addition, melanoidins were reported to have relatively stable free radicals in their molecules. The free radicals also were considered to be important for scavenging the radicals.

\section{Analysis of Reducing Power}

The reducing power activity of PSLF and the CPS is depicted in Fig. (3). There was a significant difference between PSLF $\mathrm{C}$ and the CPS. Reductones from the thermolysis of Amadori products in the primary stage of the Maillard reaction were mainly responsible for the production of reducing power in the reaction. The higher reducing power of the reaction mixture was determined by the higher absorbance [45].

The $\mathrm{Fe}^{3+}$ ions which were added to the Maillard reaction product would occur the electron transfer process and the ions would be reduced to $\mathrm{Fe}^{2+}$. The $\mathrm{Fe}^{2+}$ ions which were formed in the acidic solution, where a stable red coloured complex solution was produced. It is possible for $\mathrm{Fe}^{2+}$ ions to generate the radicals' protons or by redox processes with suitable Maillard reaction products, such as sugar, reductones or phenols which involved the reduction of the $\mathrm{Fe}^{3+}$ ions themselves to $\mathrm{Fe}^{2+}$ ions [46]. Reductones from PSLF may occur in the electron transfer process, involving the reduction of $\mathrm{Fe}^{3+}$ ions to $\mathrm{Fe}^{2+}$ ions. PSLF formulation containing the highest level of sugar (formulation C) had a greater reducing power than other formulations. The result was inconsistent with Benjakul, et al. [28] which reported that the Maillard reaction product which had the highest concentration and the most reactive reducing sugar, possessed greater reducing powers. The result revealed that Maillard reaction products from PSLF could function as electron donors. Yoshimura et al. [47] reported that Maillard reaction products from a glucose-amino acid mixture had a higher reducing power, especially when the heating time was increased. Hydroxyl group of MRP plays a role in the reducing activity.

\section{Analysis of TBA}

From Fig. (4), all formulations of PSLF were able to inhibit the lipid oxidation. Formulation $\mathrm{C}$ had the highest antioxidant activity (28.18\%). However, there was no

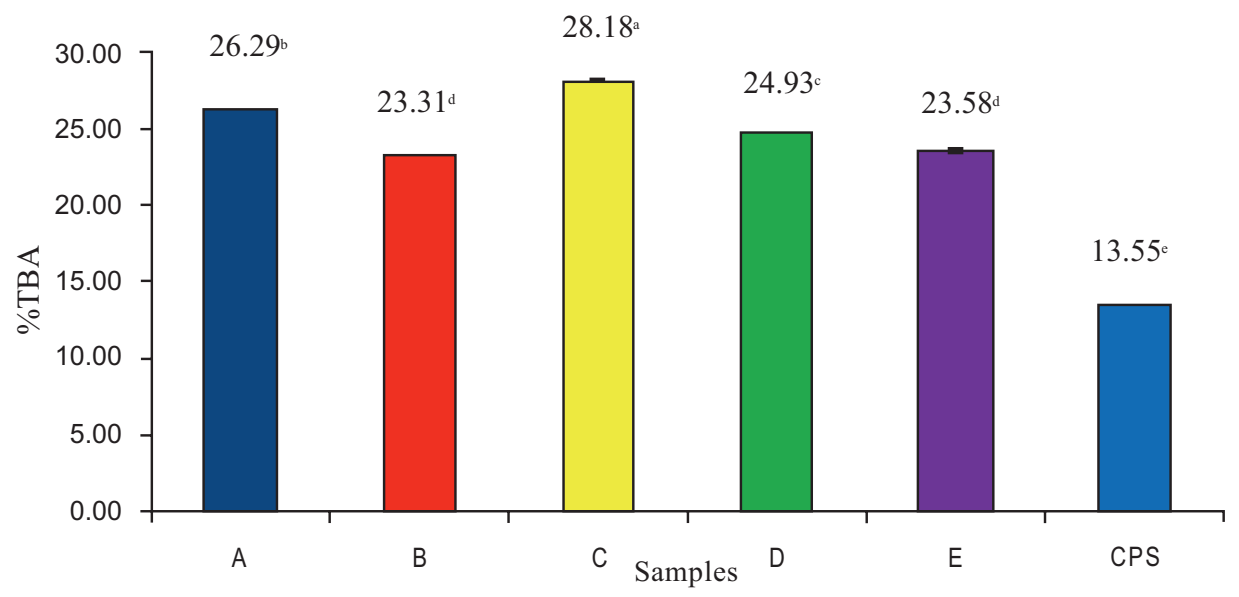

Fig. (4). Percentage (\%) of Thiobarbituric Acid (TBA) test of Various Formulations of Palm Sugar-Like Flavouring and Commercial Palm Sugar (CPS).

*Values are the means of triplicate analysis.

$*$ Values followed by a different superscript letter are significantly different $(\mathrm{p}<0.05)$. 
significant difference between all samples of PSLF ( $p>0.05$ ) and lipid oxidation was enhanced by heat, light, heavy metals and the presence of pigments. A model lipid system which contained linoleic acid in ethanol had been used to determine the antioxidant activity ability of MRP which measures the inhibition of linoleic acid oxidation. Antioxidants exert their effect by donating electrons or hydrogen atoms to free radicals containing lipids and by forming antioxidant-lipid complexes [48].

The antioxidants from MRP, inactive reactive radicals at the initial steps of the autooxidation of the linoleic acid system, thus, avoid the propagation of the radical chain reaction [49]. Most Maillard reaction products had an antioxidant effect on the TBA test and some MRP had even greater antioxidant effects than others. According to Bedinghaus and Ockerman [14], the antioxidant potential of MRP showed that materials from natural precursors, for example, histidine, lysine and tryptophan can be used in cooked product, such as meat.

From Norimasa et al. [50], the isolated reductones from the reaction mixture of aldohexoses and secondary amines were effective for inhibiting autooxidation of several kinds of vegetable oils. The study had been conducted by using the Maillard reaction product, where the effect of browning reaction solution on TBA value of linoleic acid was compared to the effect on peroxide values, where the TBA value gave a decreasing effect as well as peroxide value. Subsequently, this indicated that Maillard reaction products inhibited the formation of peroxides or/and carbonyl compounds. Accordingly, the peroxide value decreasing effect of the Maillard reaction products was considered to be responsible for the antioxidant activity [51].

Although, the antioxidative mechanism of the Maillard reaction product is still unclear, it is thought that the reductone structures, the electron donor property, the chelating properties of melanoidins against transition metals, as well as the scavenging activity of Amadori compounds and melanoidins against reactive species are important factors in promoting the inhibition of lipid and phenolic oxidation reactions [52].

\section{CONCLUSION}

The $\mathrm{pH}$ of PSLF showed the pronounced effect on the Maillard reaction. The Maillard reaction product prepared by heating the mixture of PSLF with lower pHs showed a higher antioxidant activity. Basically, the antioxidant activity moved proportionally with the increasing absorbance of browning intensity at $420 \mathrm{~nm}$. Concentration of sucrose in the mixture plays an important role as it contributed to the formation of the browning process. PSLF with formulation C (Sucrose $12.96 \mathrm{mmol}$, Asparagine $2.53 \mathrm{mmol}$, Glutamine $2.59 \mathrm{mmol}$, Arginine $0.62 \mathrm{mmol}$ and lysine $0.48 \mathrm{mmol}$ ) depicted the highest antioxidant activity as compared to other formulations and CPS.

\section{ACKNOWLEDGEMENTS}

The authors would like to express their gratitude to the Ministry of Science, Technology and Innovation, Malaysia for the funding of 05-01-02-SF0049 project as well as the Faculty of Science and Technology, University of Kebangsaan Malaysia.

\section{REFERENCES}

[1] Borelli RC, Mennella C, Barba F, et al. Characterization of coloured compounds obtained by enzymatic extraction of bakery products. Food Chem Toxicol 2003; 41: 1367-74.

[2] Wagner KH, Derkits S, Herr M, Schuh W, Elmadfa I. Antioxidant potential of melainoidins isolated from a roasted glucose-glycine model. Food Chem 2002; 78: 375-82.

[3] Jing H, Kits DD. Chemical and biochemical properties of caseinsugar Maillard reaction products. Food Chem Toxicol 2002; 40: 1007-15.

[4] Yoo MA, Kim HW, Kim KH, Kang MH. Antioxidant effect of brown substances separated from defatted roasted sesame dregs. Food Sci Biotechnol 2004; 13: 274-8.

[5] Nicoli MC, Anese M, Manzocco L, Lerici CR. Antioxidant properties of coffee brews in relation to the roasting degree. LebensmittelWiss Technol 1997; 30: 292-7.

[6] Woffenden HM, Ames JM, Chandra S. Relationship between antioxidants activities, colour and flavour compounds of crystal malt extracts. J Agric Food Chem 2001; 49: 5524-30.

[7] Morales FJ, van Boekel MAJS. A study on advanced Maillard reaction in heated casein/sugar solutions: colour formation. Int Dairy J 1998; 8: 907-15.

[8] Yusuf Y, Romeo T. Antioxidant activity of water-soluble Maillard reaction products. Food Chem 2005; 93: 273-8.

[9] Wijewickreme AN, Kitts DD. Metal chelating and antioxidant activity of Maillard reaction products. Adv Exp Med Biol 1998; 434: 245-54.

[10] Monti SM, Ritieni A, Graziani G, et al. LC-MS analysis \& antioxidative efficiency of Maillard reaction products from a lactoselysine model system. J Agric Food Chem 1999; 47: 1506-13.

[11] Hayase F, Shibuya T, Sato J, Yamamoto M. Effects of oxygen \& transition metals on advanced Millard reaction of proteins with glucose. Biosci Biotechnol Biochem 1996; 60: 1820-5.

[12] Monzocco L, Calligaris S, Mastrocola D, Nicoli MC, Lerici CR. Review of nonenzymatic browning \& antioxidant capacity in processed food. Trends Food Sci Technol 2001; 11: 340-6.

[13] Alfawaz M, Smith JS, Jeon IJ. Maillard reaction products as antioxidants in precooked ground beef. Food Chem 1994; 51: 311-8.

[14] Bedinghaus AJ, Ockerman HW. Antioxidative Maillard reaction products from reducing sigars and free amino acids in cooked ground patties. J Food Sci 1995; 60: 405-7.

[15] Tanaka M, Chiu WK, Nagashima Y, Taguchi T. Inhibitory effect of the Maillard reaction products towards lipid oxidation. Tokyo Uni Fish 1992; 79: 135-41.

[16] Ho CW, Wan Aida WM, Maskat MY, Osman H. Comparison of aroma quality between palm sugar-like flavouring and traditional palm sugar. Sains Malaysiana 2007; 36(1): 83-9.

[17] Ajandouz EH, Tchiakpe LS, Ore FD, Benajiba A, Pilgserver A. Effects of $\mathrm{pH}$ on caramelization and Maillard reaction kinetics in fructose-lysine model systems. J Food Sci 2001; 66: 926-31.

[18] Wittayachai L, Benjakul S, Tanaka M. Chracteristic and antioxidative activity of Maillard reaction products from a porcine plasma protein-glucose model system as influenced by $\mathrm{pH}$. Food Chem 2007; 100: 667-9.

[19] Mohd Zin Z, Abd Hamid A, Osman A, Saari N. Antioxidative activities of chromatographic fractions obtained from root, fruit and leaf of Mengkudu (Morinda Citrifolia L). Food Chem 2006; 94: 169-78.

[20] Kikuzaki H, Nakatani N. Antioxidant effects of some ginger constituents. J Food Sci 1993; 58: 1407-10.

[21] Shih-Chuan L, Deng-Jye Y, Shu-Yi J, Chia-hung H, Sy-Lin C. Kinetics of colour development, $\mathrm{pH}$, decreasing, and anti-oxidative activity reduction of Maillard reaction in galactose/glycine model system. Food Chem 2008; 108: 533-41.

[22] Sara IFSM, Wim MFJ, van Boekel MAJS. A review of Maillard reaction in food and implications to kinetic modelling. Trends Food Sci Technol 2001; 11: 364-73.

[23] van Boekel MAJS, Brands C. Heating of sugar-casein solutions : Isomeriztion and Maillard Reactions. In: O'Brien J, Nursten HE, Crabbe MJC, Ames JM, Eds. The Maillard reaction in food and medicine. Cambridge: Royal Society of Chemistry 1998; pp. 154158 .

[24] Apriyantono A, Ames JM. Xylose-lysine model systems: the effect of $\mathrm{pH}$ on the volatile reaction products. J Sci Food Agric 1993; 61: 477-84. 
[25] Morales FJ, Jimenez-Perez S. Free radical scavenging capacity of MRP and related to colour and fluorescence. Food Chem 2001; 72: 119-25.

[26] Benjakul S, Wittayachai L, Friedrich B. Antioxidant activity of Maillard reaction products from a porcine plasma protein-sugar model system. Food Chem 2005; 93: 189-96.

[27] Ho CW, Wan Aida WM, Maskat MY, Osman H. Changes in volatile compounds of palm sap (Arenga pinnata) during the heating process for production of palm sugar. Food Chem 2007; 102: 1156-62 .

[28] Benjakul S, Visessangun W, Phongkanpai V, Tanaka M. Antioxidative activity of caramelization products \& their preventive effect on lipid oxidation in fish mince. Food Chem 2005; 90: 231-9.

[29] Pomeranz Y, Joghson JA, Shellenberger JA. Effect of various sugars on browning. J Food Sci 1962; 29: 350-4.

[30] Yeboah FK, Alli I, Yaylayan VA. Reactivities of D-glucose and Dfructose during glycation of bovine serum albumin. J Agric Food Chem 1999; 47: 3164-72.

[31] Baxter JH. Free amino acid stability in reducing sugar systems. J Food Sci 1995 ; 60: 405-7.

[32] Berg H, van Boekel MAJS. Degradation of lactose during heating of Milk. I Reaction pathaways. Neth Milk Diary J 1994; 48: 15775 .

[33] Naranjo GB, Malec LS, Vigo MS. Reducing sugars effect on available lysine loss of casein by moderate heat treatment. Food Chem 1998; 62: 309-13.

[34] Mastrocolo D, Marina M. Progress of the Maillard reaction and antioxidant action of Maillard reaction products in preheated model system during storage. J Agric Food Chem 2000; 48: 3555-9.

[35] Labuza TP, Baisier WM. Kinetics of nonenzymatic browning. In: Schwartzburg HG, Hartel RW, Eds. Physical chemistry of foods. New York: Marcel Dekker 1992; pp. 595-649.

[36] Brandis CMJ, Alink GM, van Boekel MAJS, Jongen WMF. Mutagenicity of heated sugar-casein systems: effect on the Maillard reaction. J Agric Food Chem 2000; 48: 2271-5.

[37] Ashoor SH, Zent JB. Maillard browning of common amino acids and sugar. J Food Sci 1984; 49: 1206-7.

[38] Lertitikul W, Benjakul S, Tanaka M. Characteristics and antioxidative activity of Maillard reaction products from a porcine plasma protein-glucose model systems as influenced by $\mathrm{pH}$. Food Chem 2007; 100: 669-77.

[39] Leong LP, Shui G. An investigation of antioxidant capacity of fruits in Singapore market. Food Chem 2002; 76: 69-75.

[40] Matthaus B. Antioxidant activity of extracts obtained from residues of different oil seeds. J Agric Food Chem 2002; 50: 3444-52.

[41] Jean-Yu H, Yeong-Shin S, Hung-Min C. Antioxidative activity of roasted and defatted peanut kernels. Food Res Int 2001; 34: 639-47.

[42] Yen G, Hsieh P. Antioxidative activity and scavenging effects on active oxygen of xylose-lysine Maillard reaction products. J Sci Food Agric 1995; 67: 415-20.

[43] Murukami M, Shigeeda A, Danjo K, Yamaguchi T, Takamura H, Matoba T. Radical scavenging activity \& brightly colored pigments in the early stage of Maillard reaction. J Food Sci 2002; 67: 93-6.

[44] Hayase F, Hirashima S, Okamota G, Kato H. Scavenging of active oxygen by melanoidins. J Agric Biol Chem 1989; 53: 3383-5.

[45] Yuanxia S, Shigeru H, Masahiro O, Ken I. Antioxidative properties of custard pudding dessert containing rare hexose, D-psicose. J Food Control 2007; 18: 220-7.

[46] Cammerer B, Kroh LW. Investigation of the contribution of radicals to the mechanism of early stage of the Maillard reaction. Food Chem 1996; 57: 217-21.

[47] Yoshimura Y, Iijima T, Watanabe T, Nakazawa H. Antioxidative effect of Maillard reaction using glucose-glycine model system. J Agric Food Chem 1997; 45: 4106-9.

[48] Friedman M. Browning and its prevention: an overview. J Agric Food Chem 1996; 44: 631-53.

[49] Krings U, Berger RG. Antioxidant activity of some roasted foods. Food Chem 2001; 72: 223-9.

[50] Norimasa K, Hiromichi K, Masao F. Studies of antioxidant activity of nonenzymic browning reaction products I: Relations of colour intensity and reductones with antioxidant activity of browning reaction products. J Agric Biol Chem 1968; 32(3): 287-9.

[51] Yen GC, Wu JY. Antioxidant and radical scavenging properties of extracts from Ganoderma tsugae. Food Chem 1999; 65: 375-9.

[52] Catherine B, Sophie B, Loic L, Jaques N. Effect of glutathione and Maillard reaction products prepared from glucose or fructose with glutathione on polyphenoloxidase from apple I: enzymatic browning and enzyme activity inhibition. Food Chem 2004; 84: 223-33.

(c) Amin et al.; Licensee Bentham Open.

This is an open access article licensed under the terms of the Creative Commons Attribution Non-Commercial License (http://creativecommons.org/licenses/by-nc/3.0/) which permits unrestricted, non-commercial use, distribution and reproduction in any medium, provided the work is properly cited. 